\title{
EFFICACY OF PLATELET RICH FIBRIN ON ANGIOGENESIS
}

\author{
JIYAR MOHAMMED NAJI \\ Dept. of oral surgery,Duhok Technical Institute, University Of Poly Technique, Kurdistan Region Iraq
}

(Received: May 9, 2020; Accepted for Publication: June 10, 2020)

\begin{abstract}
In this experiment we used platelet-rich fibrin (L-PRF) with the protocol of its production, in this study we tried to investigate the angiogenetic efficacy of L-PRF on s soft tissue. Blood samples of 8 sheep were used to establish the protocol of the L-PRF formation to develop the work. The mucoperiosteal flaps were filled with autologous L-PRF in the mandible and maxillary jaws of the sheep.

Samples taken from the surgical sites stained with haematoxylin and eosin for diagnosis of the sections, then immunohistological tests were confirmed on these sections. We noticed that after 14 days of membranes implantation there was no significant differences between their histological sections. While in histological section of $\mathbf{2 8}$ days, the sections with PRF has more angiogenic effect in soft tissue with much and more organized vessels in compare with control one.
\end{abstract}

KEYWORDS: platelet rich fibrin, angiogenesis.

\section{INTRODUCTION}

$\mathbf{L}$ eukocyte- and Platelet-Rich Fibrin (LPRF) is an autologous platelet concentrate, consisting of a fibrin matrix that contain great amount of platelets, leukocytes and cytokines and growth factors ${ }^{l}$. As other types of platelets concentrates are known to have an effect on angiogenesis, we tried in this study to explore the effect of this of L-PRF.

It is known that L-PRF can be produced with one-step centrifugation ( $400 \mathrm{~g}-12 \mathrm{~min})$ and no biochemical manipulation is needed ${ }^{2-3}$. All the three different components of L-PRF can influence the process of angiogenesis. White blood cells present in L-PRF, secrets tubules forming molecules ${ }^{3-4}$. On the other hand the platelets release growth factors ${ }^{3-5}$. The fibrin matrix itself also contributes to the angiogenic potential of L-PRF, by acting as scaffold attracting the released molecules. ${ }^{6-7}$. Recently many experiments have studied the other platelets derivatives effect on the process of angiogenesis, where platelet rich plasma (PRP) potentiates endothelial proliferation ${ }^{8-9}$, migration, and tube formation ${ }^{10}$. Also there were trials on platelet rich fibrin matrix (PRFM) effect on angiogenesis in vitro ${ }^{11}$. The aim of this study is to evaluate L-PRF effect and effect on endothelial cell proliferation, migration, and tube formation in vivo.

\section{MATERIAL AND METHODS}

The study was carried out on ten adult local breed male sheep (rams), their age ranged between (10-12) months and their body weight ranged from $(31-55) \mathrm{kg}$.

The rams were housed indoors in concrete stalls in the animals' farm of the college of veterinary medicine/Dohuk university fourteen days before surgery to become adapted to the farm condition. The rams were subjected to a carefull clinical examination and complete blood picture test is taken for them to asure their health status. The study was approved by ethical committee of Dohuk university.

The rams were allowed free access to hay and water. They were administered twice daily. The animals were identified with numbered plastic ear tags.

\section{Preparation of L-PRF membranes and operations}

After the L-PRF clot that was most suitable for use was clinically established (centrifugation at $3500 \mathrm{rpm}$ for $15 \mathrm{~min}$ ) blood samples from 10 rams were used for the L-PRF operations.

Food was stopped from the rams for 36 hours and water for 12 hours before the operation. The skin over one side of the face (over the nasal, maxillary, and mandibular bones) was prepared aseptically by clipping, shaving and application of povidone iodine.

Blood was rapidly collected and immediately centrifuged at $3500 \mathrm{rpm}$ for $15 \mathrm{~min}$. After centrifugation, clots were removed from the tubes using sterile tweezers, separated from the base of red blood cells (RBC), and pressed between two pieces of gauze fig (1). 


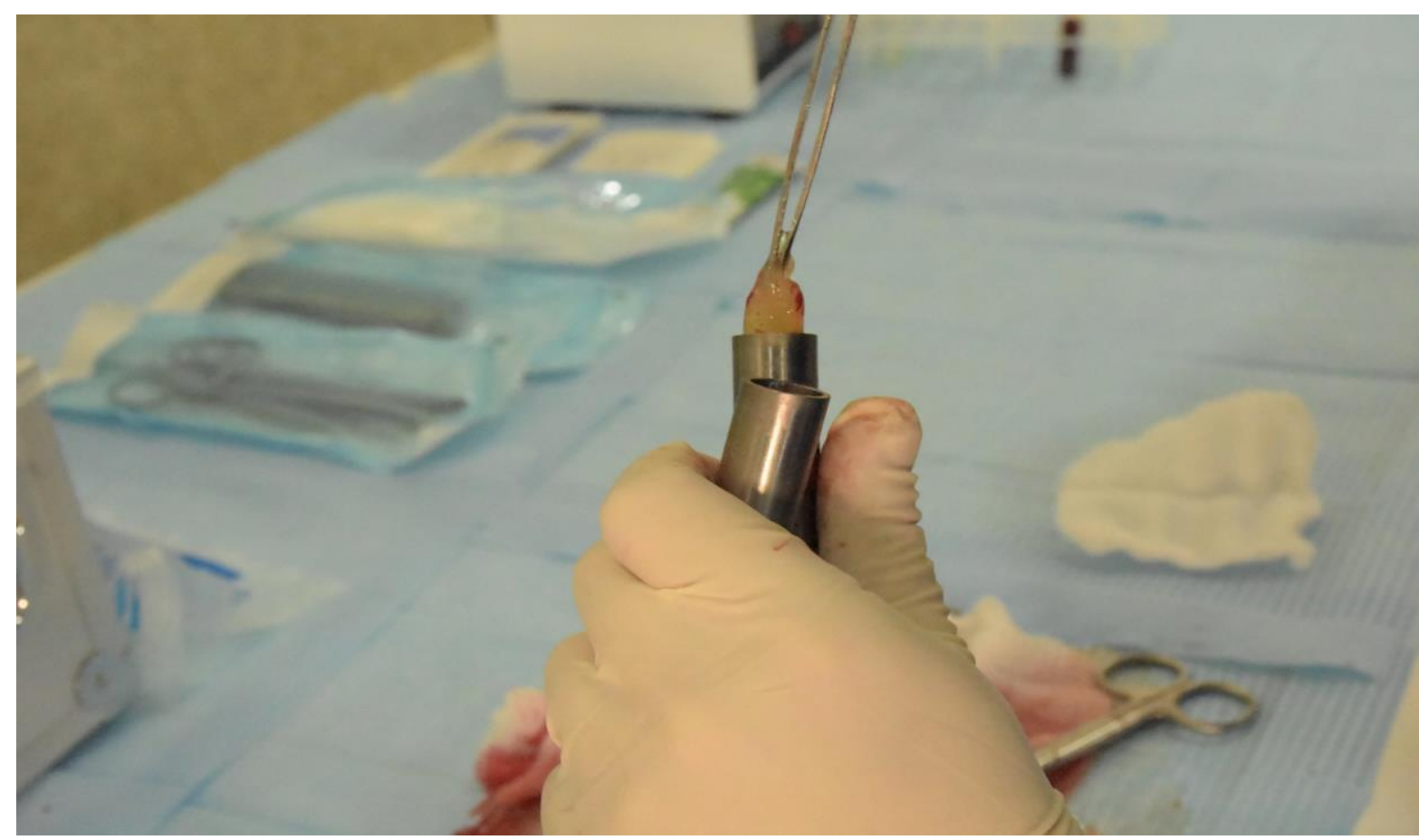

Fig. (1): platelet rich fibrin gel

Atropine sulphate (atrovap. Jordan) was given intramuscularly in a dose of $0.1 \mathrm{mg} / \mathrm{kg}$ body weight 10 minutes before induction of the anesthesia. All animals were operated on under general anesthesia induced by combination of xylazine (xyla. Interchemie Holland) in a dose of $0.2 \mathrm{mg} / \mathrm{kg}$ and ketamine hydrochloride (Ketalrom, romvac comp. Romania) in a dose of $22 \mathrm{mg} / \mathrm{kg}$ given intramuscularly. Lidocaine $2 \%$ (Laborale. India) was locally in filtered along the proposed lines of incision with infraorbital and mental nerve block.

On the day of operation, procaine penicillin and streptomycin sulphate combination (Pens \& strep norbrook. UK) was given intramuscularly in a dose of $24 \mathrm{mg} / \mathrm{kg}$ and $30 \mathrm{mg} / \mathrm{kg}$ respectively
1 hour before the operation and continued for 4 postoperative days.

The animals were kept in lateral position and the surgical area was covered with sterile drapes. to expose the maxillary and mandibular bones, two skin incisions were made, $10 \mathrm{~cm}$ each, one over the lateral surface of maxillary bone Fig (2) and the other one over the lateral aspect of the body of mandible. To create periosteal pockets, two periosteal incisions were made over each bone, each of $1 \mathrm{~cm}$ long and $1 \mathrm{~cm}$ apart, the periosteum was then elevated from the bone by periosteal elevators. The posterior periosteal pocket was filled with L-PRF membrane and the anterior pocket is left empty and considered as a control

Fig

(3). 


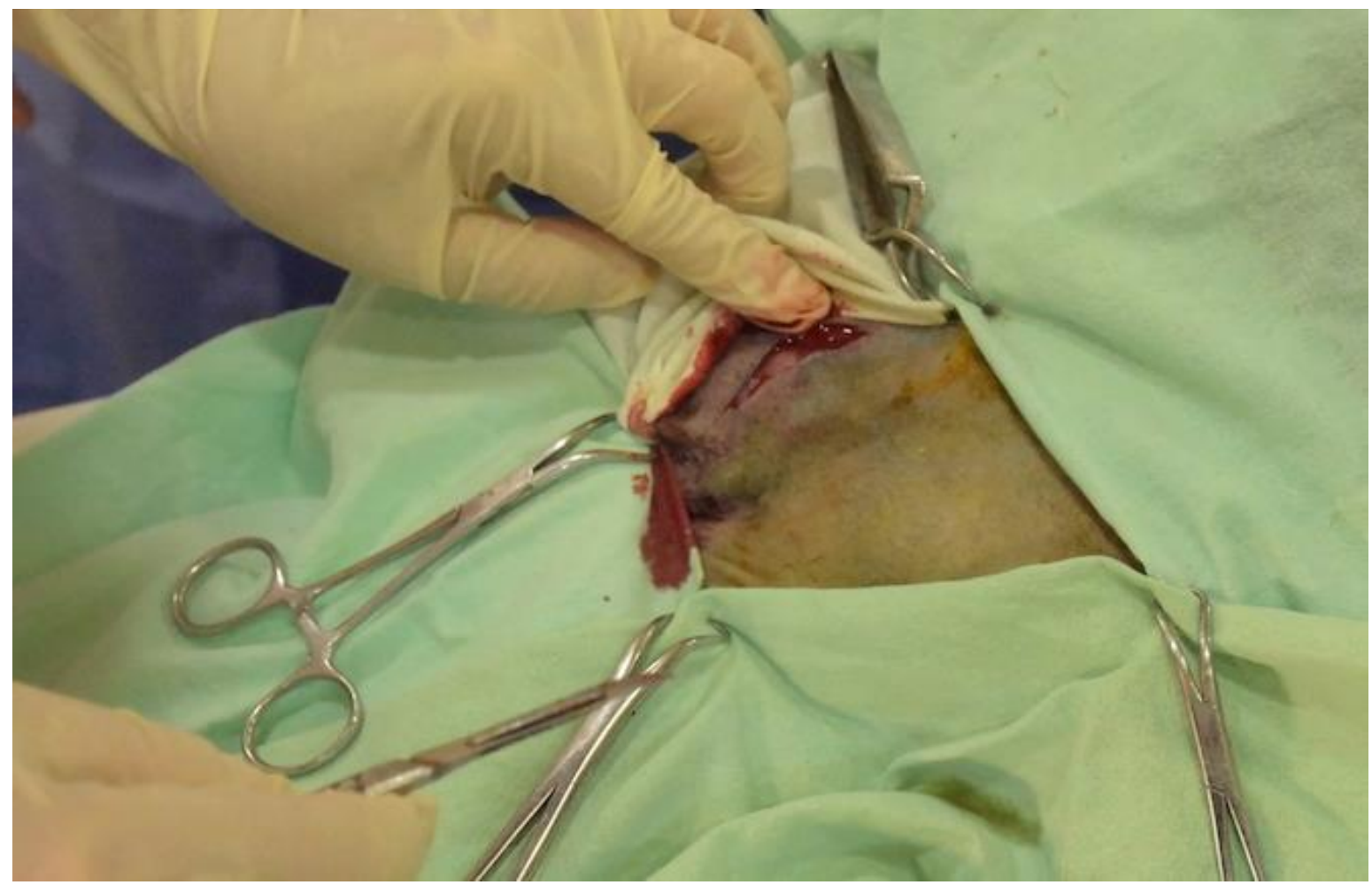

Fig. (2): Incision in the maxillary area

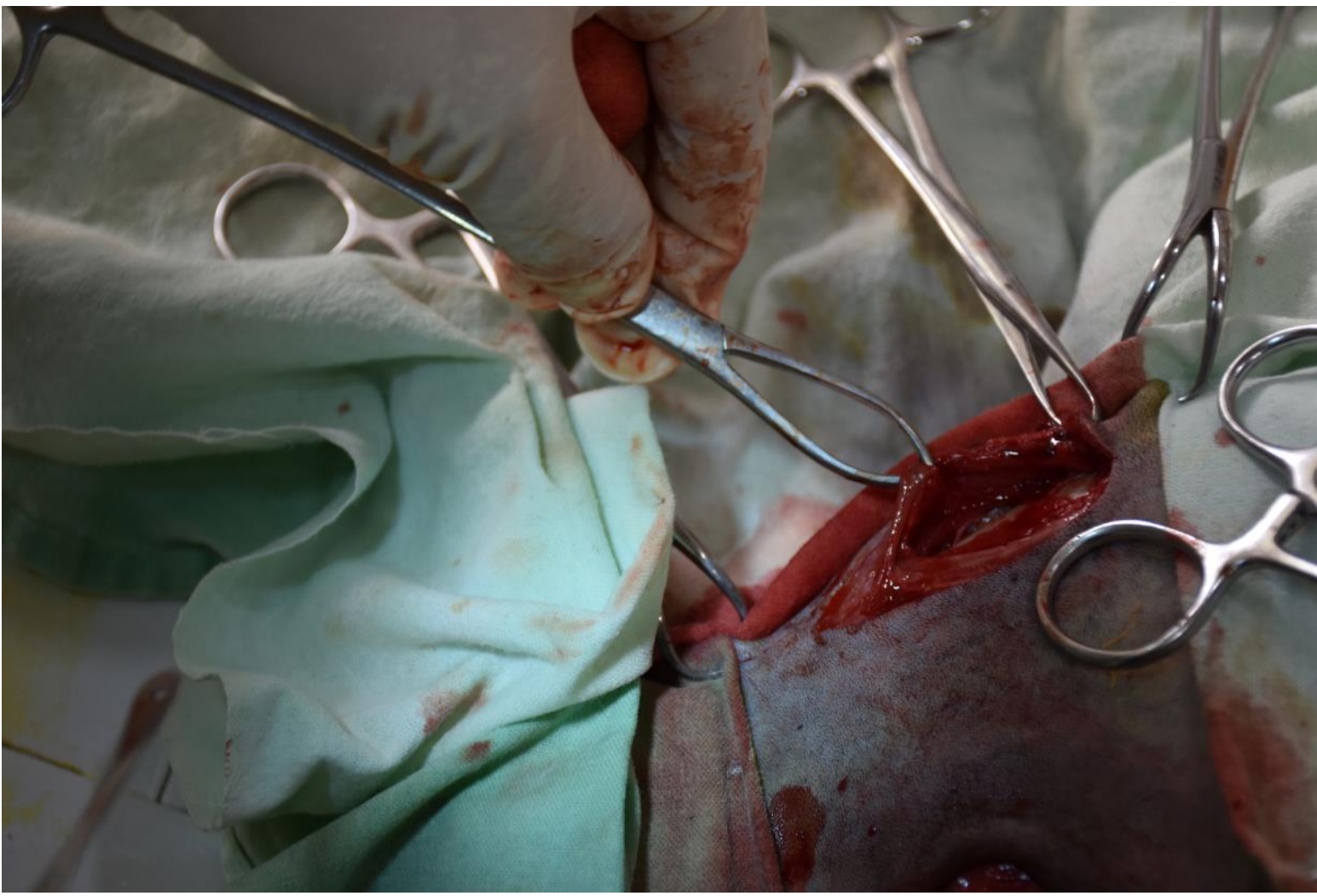

Fig. (3): subperiosteal pockets.

The periosteal incisions were closed by simple interrupted pattern and the subcutaneous tissue was closed with simple continuous pattern. Polyglycolic suture No.0 polypropylene.
Fourteen days later the same surgical procedure was performed for exposing the maxilla and mandible of the left side of face. The animals were kept in separate stalls and jiarnaji@gmail.com 
examined daily until removal of skin stitches at the $10^{\text {th }}$ postoperative day.

The animals were scarified and the samples were collected at day 14and 28 after the operation. The specimens were preserved in a $10 \%$ formaldehyde solution $24-72 \mathrm{~h}$ after extraction.

\section{Histological processing for light microscopy}

Samples were taken from the sites that had been filled with L-PRF were dehydrated in increasing gradients of alcohol $(70 \%, 95 \%$, and $100 \%$ ) and sited in toluene before paraffin inclusion. For each soft tissue sample, a series of 5 successive sections were achieved according to the long axis of the tissue. These sections were stained with haematoxylin and eosin for histological positioning and then stained with OPN to investigate the vascularization.

\section{RESULTS}

We have found no significant differences between the samples on the fourteenth day (fig 3). While, on twenty-eight days when we compared the control and the PRF histological sections we found that in case of PRF sections more inflammation cells versus lesser inflammation cell in case of control sections. on the other hand, blood vessels where more organized and assemble in case of PRF histological section versus control ones, and we've seen that spaces between collagen bundles in case of control sections are more and bigger than those of PRF sections. Fig. (4).

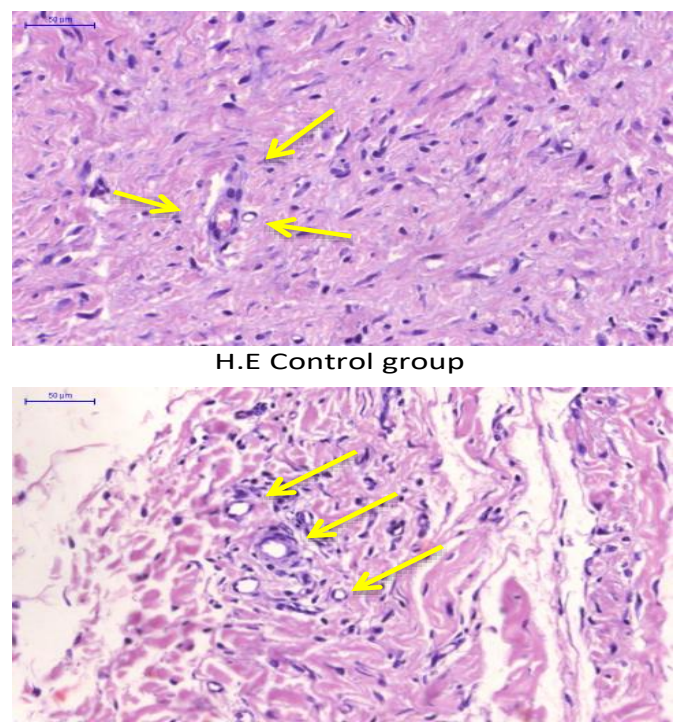

H.E 14 days

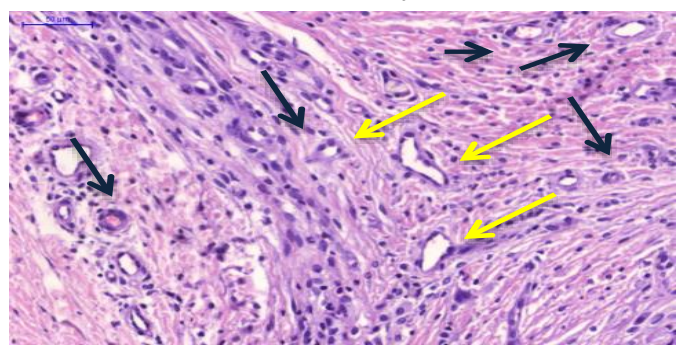

H.E 28 days

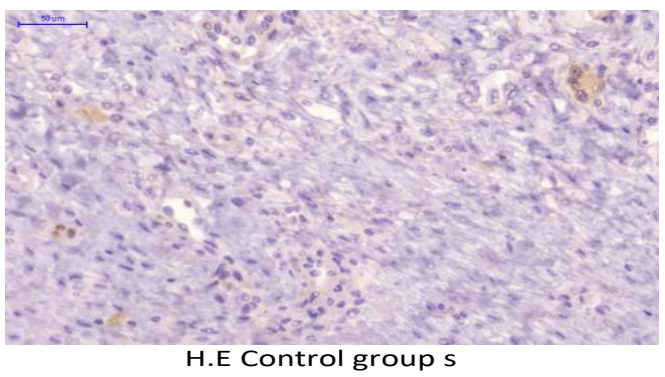

H.E Control group s

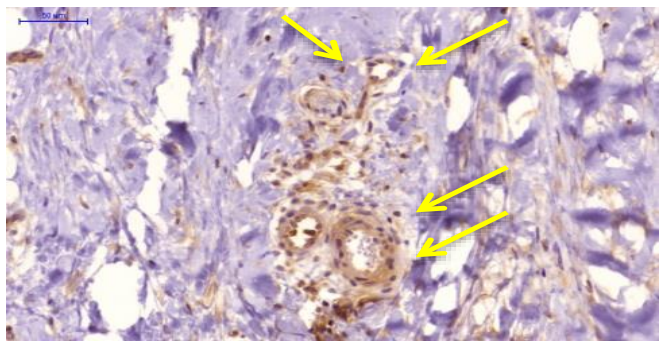

OP 14 days

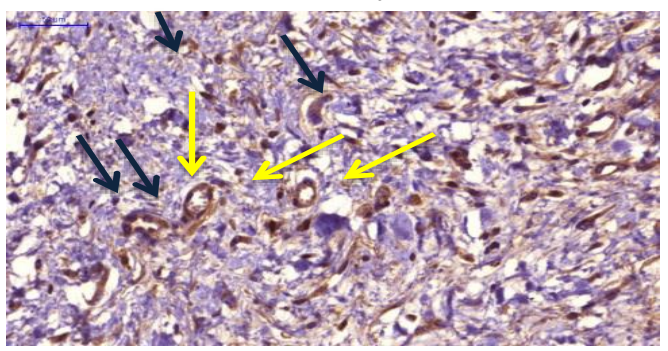

OP 28 days

Fig. (4): Shows the vascularization in different times. In the first row which representing the control group there is no vessels except that the pre existing vessel referred to it by yellow arrows. In the second row which representing after 14 days PRF insertion shows newly formed tubules. In the third row which representing after 28 days PRF insertion shows mature tubes referred to it by yellow arrows and also newly formed tubules referred to it by black arrows. 


\section{DISCUSSION}

Angiogenesis is absolutely necessary for wound healing and tissue regeneration. However, impaired or restricted angiogenesis can result in ischemic diseases or chronic wounds such as in diabetes. As well as, for tissue engineering and bone healing angiogenesis is key to avoid apoptosis and necrosis of the implanted and newly formed tissues ${ }^{12,13}$. Growth factors and other mediators released by activated platelets play an indispensable role in tissue regeneration and revascularization; therefore platelet concentrates constitute an important therapeutic tool in regeneration ${ }^{14}$. L-PRF consists of three different components, each of them influence angiogenesis and wound healing. The white blood cells(WBC) present in L-PRF, contain neutrophils and macrophages, consider as pro-angiogenic molecules ${ }_{15,16}$. Platelets are known to release an excessive amount of growth factors such as fibroblast growth factor-2 (FGF2 ), Platelet-derived growth factor (PDGF), vascular endothelial cell growth factor (VEGF) and cytokines ${ }^{17,18}$. The fibrin matrix also cause the angiogenic potential of L-PRF. By capturing secreted molecules, the fibrin matrix contributes a continuous secretion of these molecules with time ${ }^{19}$. Recently many studies have explored the angiogenic and regenerative efficacy of other platelet derivatives. As in case of that platelet rich plasma (PRP) has been proved to improve endothelial proliferation ${ }^{20}$, migration, and tube formation ${ }^{21}$. PRP also enhance wound healing in preclinical animal models ${ }^{22}$. So far only few reports searched the effect of PRFM on angiogenesis in vitro $^{23}$. In our study we observed the same effect of PRF on angiogenesis,

\section{CONCLUSION}

We showed that L-PRF is able to induce endothelial cell proliferation, migration and tubulogenesis In spite of that PRP has already been reported to enhance angiogenesis, and in our study we reported same effects of L-PRF. This study leads to the fact that the LPRF could works as an aid in wound healing via its ability enhancing anginogenesis in oral and maxillofacial surgery, implantology, and periodontology.

\section{REFERENCES}

- Anitua E, Sánchez M, Nurden AT, Nurden P, Orive G, Andia I. New insights into and novel applications for platelet-rich fibrin therapies. Trends Biotechnol 2006;24:227-34.

- Dohan DM, Choukroun J, Diss A, et al. Plateletrich fibrin (PRF): a second-generation platelet concentrate. Part III: leucocyte activation: a new feature for platelet concentrates? Oral Surg Oral Med Oral Pathol Oral Radiol Endod 2006;101:e51-5.

- Choukroun J, Diss A, Simonpieri A, et al. Plateletrich fibrin (PRF): a second-generation platelet concentrate. Part IV: clinical effects on tissue healing. Oral Surg Oral Med Oral Pathol Oral Radiol Endod 2006;101:e56-60.

- Sharma A, Pradeep AR. Autologous platelet rich fibrin in the treatment of mandibular degree II furcation defects: a randomized clinical trial. $J$ Periodontol 2011;82:1396-403.

- Simonpieri A, Choukroun J, Del Corso M, Sammartino G, Dohan Ehrenfest DM. Simultaneous sinus-lift and implantation using microthreaded implants and leukocyte- and platelet-rich fibrin as sole grafting material: a six-year experience. Implant Dent 2011;20:212.

- Braccini F, Tardivet L, Dohan Ehrenfest DM. The relevance of Choukroun's Platelet-Rich Fibrin (PRF) during middle ear surgery: preliminary results. Rev Laryngol Otol Rhinol (Bord) 2009;130:175-80 [in French].

- Baeyens W, Glineur R, Evrard L. The use of platelet concentrates: platelet-rich plasma (PRP) and platelet-rich fibrin (PRF) in bone reconstruction prior to dental implant surgery. Rev Med Brux 2010;31:521-7 [in French].

- Inchingolo F, Tatullo M, Marrelli M. Trial with Platelet-Rich Fibrin and Bio-Oss used as grafting materials in the treatment of the severe maxillar bone atrophy: clinical and radiological evaluations. Eur Rev Med Pharmacol Sci 2010;14:1075-84.

- Gürbüzer B, Pikdöken L, Tunali M, et al. Scintigraphic evaluation of osteoblastic activity in extraction sockets treated with platelet-rich fibrin. J Oral Maxillofac Surg 2010;68:980-9.

- O'Connell SM. Safety issues associated with platelet-rich fibrin method. Oral Surg Oral Med Oral Pathol Oral Radiol Endod 2007;103:587-93.

- Dohan Ehrenfest DM, Rasmusson L, Albrektsson T. Classification of platelet concentrates: from pure platelet-rich plasma (P-PRP) to leucocyte- and platelet-rich fibrin (L-PRF). Trends Biotechnol 2009;27:158-67.

- Mammoto, T., Jiang, A., Jiang, E. \& Mammoto, A. Platelet rich plasma extract promotes 
angiogenesis through the angiopoietin1itépiTie2 pathway. Microvasc Res 89, 15-24, https://doi.org/10.1016/j.mvr.2013.04.008 (2013). is ispi:

- Carmeliet, P. Mechanisms of angiogenesis and arteriogenesis. Nat Med 6, 389-395, https://doi.org/10.1038/74651 (2000).

- Roy, S. et al. Platelet-rich brin matrix improves wound angiogenesis via inducing endothelial cell proliferation. Wound Repair istiegen 19, 753-766, https://doi.org/10.1111/j.1524-

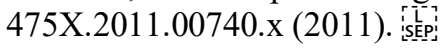

$-\mathrm{Ko}, \mathrm{H}$. M. et al. Involvement of matrix metalloproteinase-9 in platelet-activating factor-induced angiogenesis. FEBS Lett 579, itépi2369-2375,

https://doi.org/10.1016/j.febslet.2005.03.035

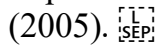

- Benelli, R., Albini, A. \& Noonan, D. Neutrophils and angiogenesis: potential initiators of the

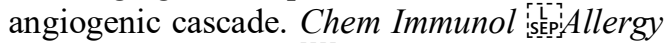

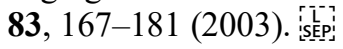

- Martinez, C. E., Smith, P. C. \& Palma Alvarado, V. A. $\mathrm{e}$ in uence of platelet-derived products on angiogenesis and tissue repair: a concise update. Front Physiol 6, 290, https://doi.org/10.3389/fphys.2015.00290

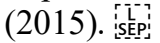

- Mishra, A., Harmon, K., Woodall, J. \& Vieira, A.
Sports medicine applications of platelet rich plasma. Curr Pharm Biotechnol 13, 1195 (2012).

- van Hinsbergh, V. W., Collen, A. \& Koolwijk, P. Role of fibrin matrix in angiogenesis. Ann NY Acad Sci 936, 426-437 (2001). išmp.

- Bertrand-Duchesne, M. P., Grenier, D. \& Gagnon, G. Epidermal growth factor released from platelet-rich plasma promotes cell proliferation in vitro. $J$ Periodontal Res 45, 87-93, https://doi.org/10.1111/j.1600-

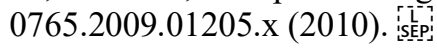

- Zhou, B. et al. Rapidly in situ forming platelet-rich plasma gel enhances angiogenic responses and augments early wound healing is ípepa er open abdomen. Gastroenterol Res Pract 2013, 926764, https://doi.org/10.1155/2013/926764 (2013). iLẸ:

- Notodihardjo, P. V. et al. Gelatin hydrogel impregnated with platelet-rich plasma releasate promotes angiogenesis and wound SSEp phealing in murine model. J Artif Organs 18, 64-71, https://doi.org/10.1007/s10047-014-

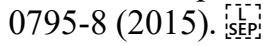

- Roy, S. et al. Platelet-rich brin matrix improves wound angiogenesis via inducing endothelial cell proliferation. Wound Repair 753-766, https://doi.org/10.1111/j.1524475X.2011.00740.x (2011). 